\title{
Myelofibrosis as a cause of pancytopenia in systemic lupus erythematosus
}

\author{
HELENA M DALY, GL SCOTT \\ From the Department of Clinical Haematology, Bristol Royal Infirmary, Bristol BS2 8HW
}

SUMMARY A 16-year-old Iranian girl presented with the clinical features of systemic lupus erythematosus and pancytopenia. The pancytopenia was found to be due to myelofibrosis. Both the pancytopenia and marrow fibrosis were reversed by treatment with corticosteroids.

Haematological abnormalities are common in SLE and are due to various mechanisms. Pancytopenia is uncommon' and has usually been attributed to folate deficiency secondary to haemolysis, autoimmunity, infection or due to drug treatment of the underlying disease. In the case described below pancytopenia was due to bone marrow fibrosis.

\section{Case report}

A 16-year-old girl was referred from Iran for management of suspected aplastic anaemia. There was a two week history of dyspnoea, epistaxis and bleeding gums. Investigations performed in Iran showed a pancytopenia with haemoglobin $(\mathrm{Hb}) 8 \mathrm{~g} / \mathrm{dl}$, white cell count (WCC) $1.2 \times 10^{9} /$, neutrophils $0.6 \times$ $10^{9} / 1$, platelets $50 \times 10^{9} / 1$, reticulocytes $23 \times 10^{9} / 1$, direct Coombs' test was negative, erythrocyte sedimentation rate (ESR) $120 \mathrm{~mm} / \mathrm{h}$. During the previous year she had complained of anorexia, weight loss and alopecia. She had a six year history of arthritis involving the joints of her hands and feet. "Rheumatism" had been diagnosed and she had received many anti-inflammatory drugs including oxyphenbutazone.

On admission she was extremely ill. There were small lymph nodes in the neck and axilla and the spleen was palpable $9 \mathrm{~cm}$ below the costal margin. The liver edge was palpable. She had epistaxis, bleeding gums and widespread purpura and ecchymoses. She also had bilateral flexor tendinitis and subcutaneous nodules in both hands. There were discrete retinal exudates bilaterally.

The blood count confirmed pancytopenia ( $\mathrm{Hb} 7 \cdot 0$ g/dl, WCC $1.7 \times 10^{9} / 1$, neutrophils $0.5 \times 10^{9} / 1$, platelets $28 \times 10^{9} / 1$, and reticulocytes $\left.36 \times 10^{9} / 1\right)$. The plasma viscosity was $2.34 \mathrm{cp}$ (normal $1.5-1.72$

Accepted for publication 14 July 1983 cp). The peripheral blood film showed marked rouleaux and tear-drop poikilocytes. Red blood cell folate and haemoglobin electrophoresis were normal. Three attempts to aspirate bone marrow at different sites were unsuccessful and yielded a "dry tap" only.

Clinically the patient was though to have SLE and in view of the failure to aspirate marrow it was thought that her pancytopenia was due to aplastic anaemia, possibly related to the oxyphenbutazone which she had received previously.

Subsequent investigations confirmed that she dị have SLE. There was polyclonal hypergammaglobulinaemia. Anti-nuclear factor antibodies of homogeneous distribution were demonstrated by indirect immunofluorescence to a titre of greater than 1280. The anti-DNA (doubled stranded) antibody binding ratio was $42 \%$ (normal less than $35 \%$ ). There was hypocomplementaemia and tests for immune complexes suggested that there was a heavy load of circulating complexes (anticomplementary activity 2, platelet aggregation 1024 (normal 0-16), C1q binding $86 \%$ (normal < 20\%)). No autoantibodies to red cells, white cells or platelets could be demonstrated.

The results of the bone marrow trephine biopsy from the posterior iliac spine was unexpected. There was marked marrow fibrosis with reduced numbers of erythroid precursors. Megakaryocytes were plentiful (Fig. 1). The reticulin content was greatly increased (Fig. 2). A trephine biopsy from the opposite side showed a similar picture confirming that the marrow was generally involved. Further attempts at aspiration from this site were again unsuccessful.

She was transfused and started on prednisolone $30 \mathrm{mg}$ daily. Within a few days her blood count started to improve and she made a rapid recovery. After one week the blood count was $\mathrm{Hb} 9.6 \mathrm{~g} / \mathrm{dl}$, WCC $2.8 \times 10^{9} / 1$, neutrophils $1.0 \times 10^{9} / 1$, platelets 


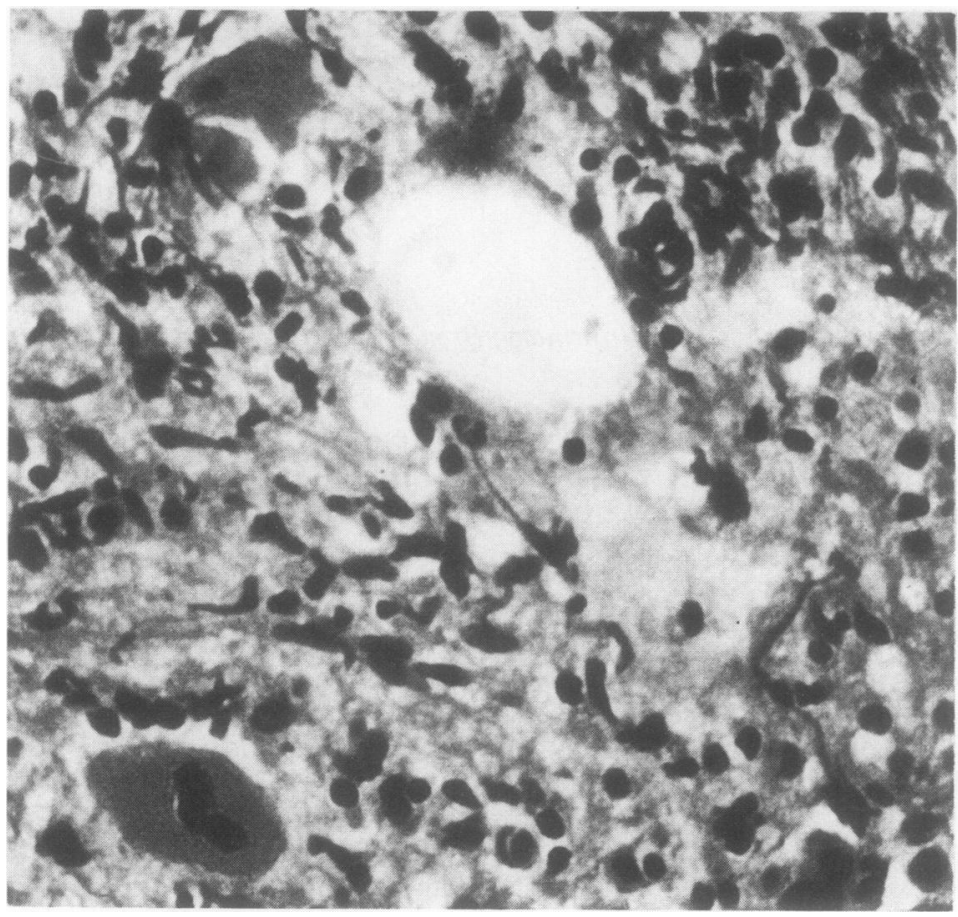

Fig. 1 Trephine biopsy at presentation showing excess fibroblasts. Haematoxylin and eosin $\times 500$.

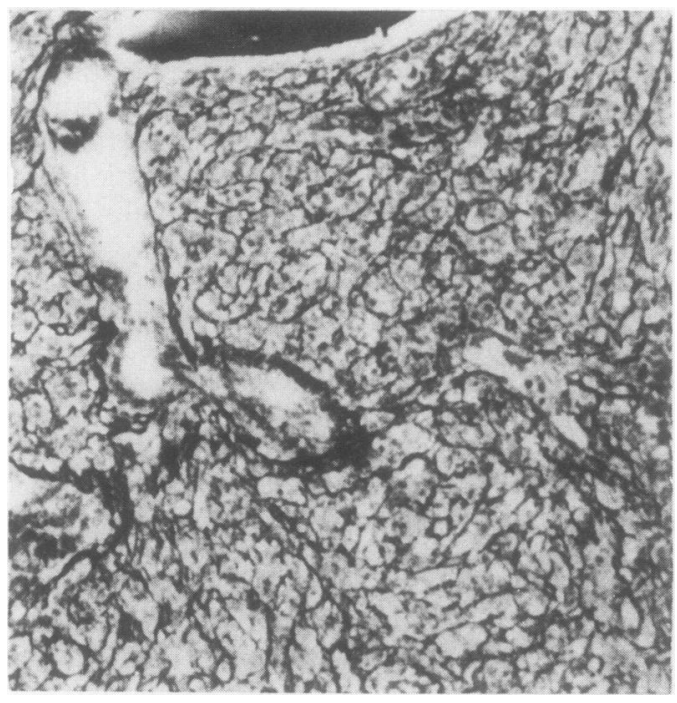

Fig. 2 Trephine biopsy at presentation showing increased reticulin. Silver impregnation $\times 125$.

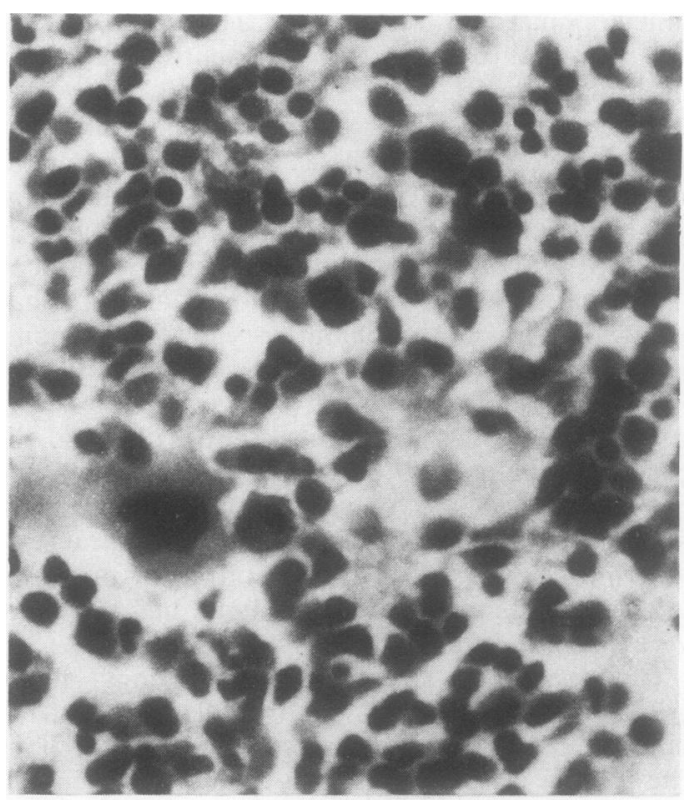

Fig. 3 Trephine biopsy after 8 weeks showing normocellular marrow. Haematoxylin and eosin $\times 500$.

\section{lin}




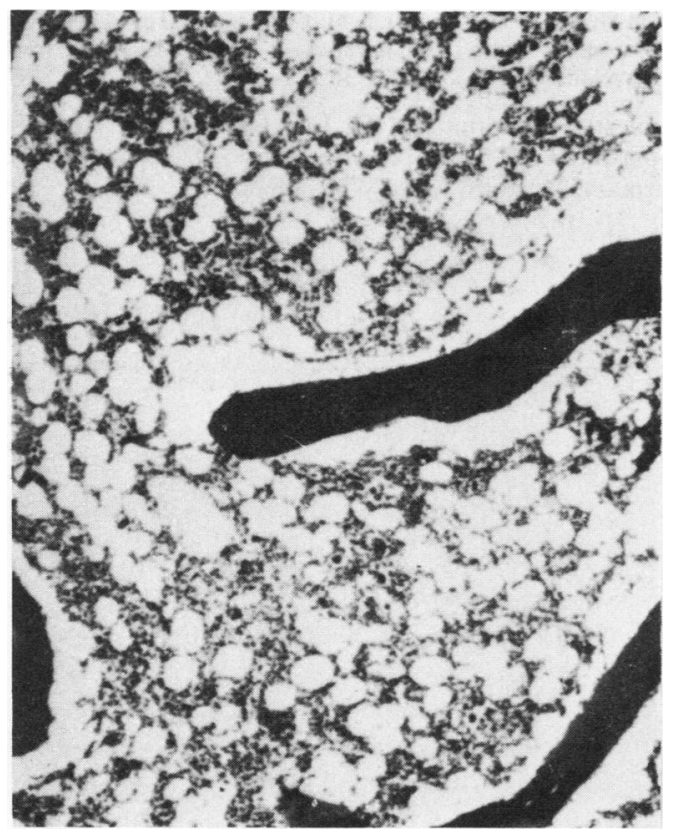

Fig. 4 Silver impregnation preparation of same trephine biopsy as Fig. 4 showing decreased reticulin $\times 125$.

$75 \times 10^{9} / 1$. The dose of prednisolone was reduced progressively. Four weeks after starting on steroids the spleen was impalpable and her $\mathrm{Hb} 12.3 \mathrm{~g} / \mathrm{dl}$, WCC $2.9 \times 10^{9} / 1$, neutrophils $1.2 \times 10^{9} / 1$, and platelets $110 \times 10^{9} / 1$. Eight weeks after starting steroids she was quite well with $\mathrm{Hb} 12 \cdot 8 \mathrm{~g} / \mathrm{dl}$, WCC $4.3 \times 10^{9} / 1$, neutrophils $3.0 \times 10^{9} / 1$, and platelets $110 \times 10^{\%} / 1$. The blood film had returned to normal with only an occasional tear drop poikilocyte. Repeat bone marrow examination was performed. On this occasion the bone marrow aspirate yielded normocellular marrow and the trephine biopsy was normocellular (Fig. 3) with a marked reduction in the amount of reticulin which was now almost normal (Fig. 4). She was continued on $10 \mathrm{mg}$ of prednisolone daily and returned to Iran for further management.

\section{Discussion}

Haematological abnormalities are common in SLE. ${ }^{2}$ They include anaemia, leucopenia and thrombocytopenia. Anaemia is the commonest abnormality occurring in more than $50 \%$ of cases. It is usually due to the anaemia of chronic disease although autoimmune haemolytic anaemia occurs in $15 \%$ of cases. Leucopenia is also common as a result of antileucocyte antibodies. Increased platelet destruction due to autoantibodies can be demonstrated in most patients but thrombocytopenia is less common occurring in 10-20\%. Pancytopenia is uncommon. ${ }^{1}$ It may be due to folate depletion secondary to haemolysis, autoimmunity, infection or due to drug treatment of the underlying disease. Pancytopenia associated with bone marrow fibrosis has not previously been described in SLE. There is one other report on bone marrow fibrosis occurring in two patients with $\mathrm{SLE}^{3}$ and both of these had a leucoerythroblastic blood picture rather than pancytopenia. One of these patients did show an improvement in the peripheral blood count following steroid therapy but the bone marrow remained fibrotic. There is also a report on myelofibrosis occurring in a patient with systemic sclerosis ${ }^{4}$ and in this case the local picture rapidly transformed into an acute process resembling acute leukaemia. This patient had received chlorambucil prior to developing fibrosis.

Myelofibrosis is usually found in association with myeloproliferative disorders or metastatic carcinoma. It has been suggested that in the former the fibrosis is due to the proliferation of an abnormal clone of cells although cytogenetic studies have failed to demonstrate the clonal abnormality in the fibroblasts. ${ }^{56}$ It seems more likely that myelofibrosis is a non-specific response to bone marrow injury or infiltration and that in the myeloproliferative disorders it is a response to uncontrolled clonal haemopoietic proliferation. In SLE the cause of myelofibrosis may be an extension of the basic lesion, vasculitis, with the bone marrow as the target organ. Aseptic necrosis of the femoral head is well described in SLE and may have a similar aetiology.

In our patient there was considerable improvement in both the peripheral blood count and the bone marrow appearances following a short course of corticosteroids. This suggests that myelofibrosis can be reversed if the underlying disease can be treated.

We report this case as we believe it to be the first in which marrow fibrosis has been shown to be the cause of pancytopenia in SLE and which has been reversed by treatment with corticosteroids. It is likely that the fibrosis was secondary to bone marrow injury from vasculitis and that like other clinical features of SLE it can be suppressed by corticosteroids.

\section{References}

\footnotetext{
' Mowat AG. Connective tissue disease. In: Haematological aspects of systemic disease. Clin Haematol 1972 ;3:586-9.

${ }^{2}$ Budman DR, Steinberg AD. Haematologic aspects of systemic lupus erythematosus. Ann Intern Med 1977;86:220-9.

${ }^{3}$ Lau KS, White JC. Myelosclerosis associated with systemic lupus
} 
erythematosus in patients in West Malaysia. J Clin Pathol 1969;22:433-8.

4 Gisser SD, Chung KB. Acute myelofibrosis of progressive systemic sclerosis. Am J Med 1979;67:151-4.

5 Jacobson RJ, Salo A, Fialkow PJ. Agogenic myeloid metaplasia. A clonal proliferation of haemopoietic stem cells with secondary myelofibrosis. Blood 1978;51:189-94.
- Van Slych EJ, Weiss L, Dully M. Chromosomal evidence for the secondary role of fibroblastic proliferation in acute myelofibrosis. Blood 1970;36:729-35.

Requests for reprints to: Dr HM Daly, Senior Registrar, Department of Clinical Haematology, Bristol Royal Infirmary, Bristol BS2 8HW, England. 